\title{
Wet oxidation of nitride layer implanted with low-energy Si ions for improved oxide- nitride-oxide memory stacks
}

V. Ioannou-Sougleridis, P. Dimitrakis, V. Em. Vamvakas, P. Normand, C. Bonafos, S. Schamm, N. Cherkashin, G. Ben Assayag, M. Perego, and M. Fanciulli

Citation: Appl. Phys. Lett. 90, 263513 (2007); doi: 10.1063/1.2752769

View online: https://doi.org/10.1063/1.2752769

View Table of Contents: http://aip.scitation.org/toc/apl/90/26

Published by the American Institute of Physics

Articles you may be interested in

Thermal oxidation of silicon nitride and silicon oxynitride films

Journal of Vacuum Science \& Technology B: Microelectronics Processing and Phenomena 7, 455 (1989); 10.1116/1.584769

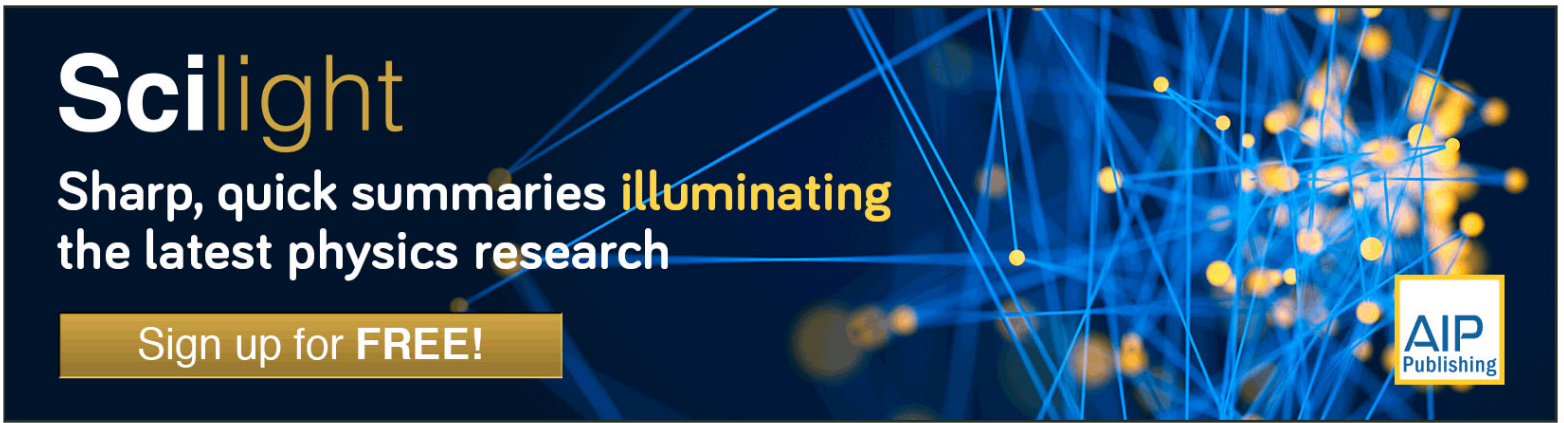




\title{
Wet oxidation of nitride layer implanted with low-energy Si ions for improved oxide-nitride-oxide memory stacks
}

\author{
V. Ioannou-Sougleridis, ${ }^{\text {a) }}$ P. Dimitrakis, V. Em. Vamvakas, and P. Normand \\ Institute of Microelectronics, NCSR "Demokritos," 15310 Aghia Paraskevi, Greece \\ C. Bonafos, S. Schamm, N. Cherkashin, and G. Ben Assayag \\ CEMES-CNRS, 29 rue J. Marvig, 31055 Toulouse, France
}

M. Perego and M. Fanciulli

MDM CNR-INFM, via c. Olivetti 2, Agrate Brianza, 20041 Milano, Italy

(Received 23 March 2007; accepted 6 June 2007; published online 29 June 2007)

\begin{abstract}
An alternative method for the formation of the top oxide in oxide-nitride-oxide dielectric stacks is proposed. This method combines low-energy $(1 \mathrm{keV})$ silicon ion implantation into a thin nitride-oxide stack and subsequent low-temperature wet oxidation $\left(850^{\circ} \mathrm{C}\right.$ for $\left.15 \mathrm{~min}\right)$. Transmission electron microscopy shows that for an implanted dose of $1.5 \times 10^{16} \mathrm{Si} \mathrm{cm}^{-2}$, an 8-nm-thick silicon oxide layer develops on the surface of the nitride-oxide stack. Time of flight secondary ion mass spectrometry reveals: (1) transformation of the implanted silicon nitride to an oxygen-rich-silicon nitride layer and (2) pilling up of nitrogen atoms at the bottom silicon/ oxide-substrate interface. The resulting oxide-nitride-oxide stack exhibits strong charge storage effects and excellent charge retention properties leading to a $1.5 \mathrm{~V}, 10 \mathrm{yr}$ extrapolated memory window at $125^{\circ} \mathrm{C}$. These results suggest that the proposed fabrication route may lead to gate dielectric stacks of substantial potential impact for mainstream nitride-based memory devices.

(C) 2007 American Institute of Physics. [DOI: 10.1063/1.2752769]
\end{abstract}

Nitride-based memory technology has the potential to fulfill the stringent requirements of nonvolatile memory cell downscaling. ${ }^{1}$ This technology exploits the presence of discrete charge storage nodes in the form of deep traps distributed in nitride materials. Due to its promising in terms of scalability, the conventional polycrystalline silicon/oxide/ nitride/oxide/silicon memory cell has regained a lot of attention nowadays. ${ }^{2,3}$

Typical fabrication of the oxide/nitride/oxide (ONO) stack consists in the growth of a thin $\mathrm{SiO}_{2}$ layer on a $\mathrm{Si}$ substrate and subsequent deposition of a $\mathrm{Si}_{3} \mathrm{~N}_{4}$ layer. The top silicon oxide is obtained by either deposition techniques or high temperature wet oxidation ${ }^{4,5}$ of the $\mathrm{Si}_{3} \mathrm{~N}_{4}$ layer. The latter approach has two main advantages. First, a thermal top oxide exhibits better insulating properties compared to a deposited oxide. Second, during the oxidation step a silicon oxynitride transition layer forms between the top oxide and the remaining silicon nitride, containing a high density of traps. This layer can efficiently accommodate a larger proportion of trapped carriers as compared to that of stoichiometric or Si-rich nitride. ${ }^{6}$ However, fabrication of functional thermal blocking oxides requires high oxidation temperatures (typically within the $1000^{\circ} \mathrm{C}$ range ${ }^{7}$ ). For deepsubmicron integration purposes, it is important to explore alternative technological routes that could lead to the formation of a thermal top oxide at lower oxidation temperatures.

In this work a method for the formation of the top oxide in ONO stacks is proposed. This method is based on lowenergy Si ion implantation into oxide-nitride (ON) structures followed by low-temperature wet oxidation. The structural and chemical properties as well as the memory performance

${ }^{\text {a) }}$ Author to whom correspondence should be addressed; electronic mail: v.ioannou@imel.demokritos.gr of the resulting ONO stacks are reported and compared to those of unimplanted ONO stacks.

$\mathrm{SiO}_{2}$ and $\mathrm{Si}_{3} \mathrm{~N}_{4}$ stacks were first formed on a 4 in. $n$-type (100) $\mathrm{Si}$ wafer. The oxide layer (referred as tunnel or bottom oxide) was grown by dry oxidation at $850{ }^{\circ} \mathrm{C}$ to a thickness of $2.8 \mathrm{~nm}$. The $\mathrm{Si}_{3} \mathrm{~N}_{4}$ layer $6 \mathrm{~nm}$ thick was deposited by low-pressure chemical vapor deposition (LPCVD) at $800{ }^{\circ} \mathrm{C}$ using a mixture of dichlorosilane $\left(\mathrm{SiH}_{2} \mathrm{Cl}_{2}\right)$ and ammonia gasses $\left(\mathrm{NH}_{3}\right)$. Subsequently, the wafer was cut in to four pieces referred hereafter as samples II and C1-C3. Sample II was implanted with $1 \mathrm{keV} \mathrm{Si}$ ions to a dose of 1.5 $\times 10^{16} \mathrm{~cm}^{-2}$. Si implantation using accelerating energy as low as $1 \mathrm{keV}$ allows for the introduction of $\mathrm{Si}$ atoms with a distribution confined in the nitride layer. Monte Carlo simulations using the TRIM code and energy-filtered transmission electron microscopy (TEM) analysis of high-temperature thermally annealed samples in $\mathrm{N}_{2}$, indicate that the peak of the implanted profile is about $2.2 \mathrm{~nm}$ from the $\mathrm{Si}_{3} \mathrm{~N}_{4}$ surface. ${ }^{8}$ In addition to Si enrichment of the implanted nitride materials, the implantation process produces a variety of defects such as vacancies, recoil $\mathrm{N}$ and $\mathrm{Si}$ atoms, and broken bonds that increase the density of reaction sites and thereby reduce the activation energy for oxidation. TRIM depth distributions of vacancies and recoil atoms exhibit a projected range of about $1.6 \mathrm{~nm}$ from the free nitride interface with tails extending up to the middle region of the tunnel oxide. While TRIM information on ion and defect distributions should be cautiously considered, especially in the case of low-energy high-dose ion implantation into thin dielectrics where a number of parameters ${ }^{9,10}$ (e.g., ion beam mixing, surface sputtering, and target swelling) contribute to the physicochemical changes of the target, one can assumed that the implantation process affects both the nitride layer and part of the tunnel oxide of sample II. Following the 


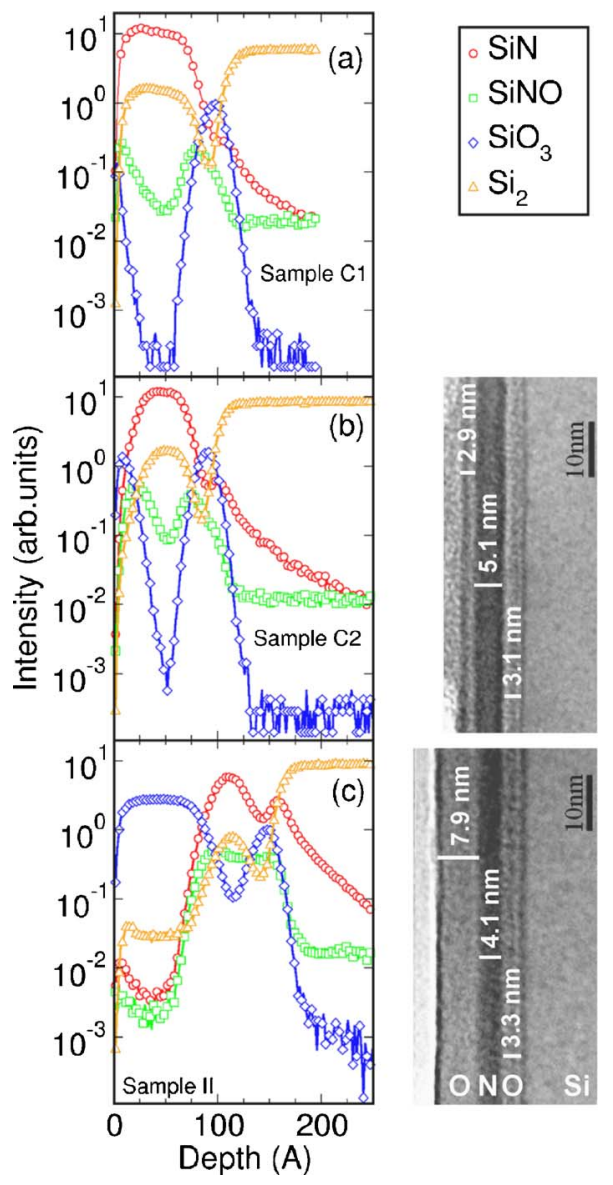

FIG. 1. (Color online) ToF-SIMS depth profiles of (a) unoxidized (sample C1), (b) wet oxidized (sample C2), and (c) Si implanted and wet oxidized (sample II) ON stacks. Defocused bright field cross-sectional TEM images are shown for samples $\mathrm{C} 2$ and II.

implantation step, sample II was thermally oxidized in wet ambient at $850^{\circ} \mathrm{C}$ for 15 min to produce the top control oxide and further thermally annealed at $950{ }^{\circ} \mathrm{C}$ in $\mathrm{N}_{2}$. The three control samples $\mathrm{C} 1-\mathrm{C} 3$ start with the non-Si-implanted ON stacks. Samples $\mathrm{C} 1$ and $\mathrm{C} 2$ consist of the dielectric stacks produced without and with the above wet oxidation step, respectively. Sample C3 refers to ONO stacks with 8-nm-thick top oxide produced by LPCVD at $700{ }^{\circ} \mathrm{C}$ using tetraethylorthosilane and subsequently, thermally annealed at $950{ }^{\circ} \mathrm{C}$ in $\mathrm{N}_{2}$. The structural and chemical characteristics of the produced ONO stacks were investigated by TEM and time of flight secondary ion mass spectroscopy (ToF-SIMS). Finally, generic metal-ONO-semiconductor (MONOS) Al gate capacitors were fabricated to study the electrical properties and memory performance of the ONO stacks.

The effect of wet oxidation on the control and implanted ON structures was examined by cross-sectional TEM in defocused bright field conditions. The method for distance measurements on such images is given in Ref. 9, with error bars of $\pm 0.5 \mathrm{~nm}$. Wet oxidation of the control sample C2 forms a thin oxide layer (mean thickness of $2.9 \mathrm{~nm}$ ) on top of the nitride layer, while the remaining nitride mean thickness is $5.1 \mathrm{~nm}$ [see Fig. 1(b)] and the thickness of the bottom oxide is around $3.1 \mathrm{~nm}$. The ONO stack of sample C2 exhibits almost identical tunnel and top oxide thicknesses. On the contrary, the Si implanted and wet oxidized ON structure (sample II) [Fig. 1(c)] presents an 8-nm-thick oxide on top of the remaining nitride layer $(4.1 \mathrm{~nm}$ thick $)$ and a bottom oxide

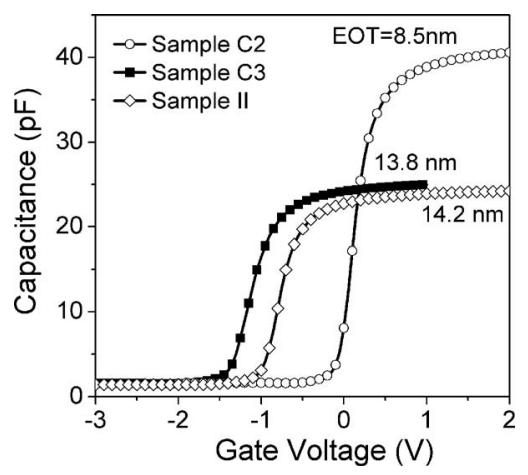

FIG. 2. Typical high-frequency $C-V$ characteristics of MONOS capacitors from samples $\mathrm{C} 2, \mathrm{C} 3$, and II.

with a mean thickness of $3.3 \mathrm{~nm}$. In addition, the interface of the top oxide with the nitride layer is flat and parallel to the bottom oxide-substrate interface indicating that the oxidation front is uniform.

Depth profile chemical compositions of the samples were obtained by ToF-SIMS. Sputtering was performed by $\mathrm{Cs}^{+}$ions at $0.5 \mathrm{keV}$ energy and $34 \mathrm{nA}$ beam current. The analysis was made in negative polarity, using $\mathrm{Ga}^{+}$at $25 \mathrm{keV}$ energy and a current of $1.1 \mathrm{pA}$. Figure 1 shows the signals of the $\mathrm{SiN}, \mathrm{SiON}, \mathrm{SiO}_{3}$, and $\mathrm{Si}_{2}$ secondary ions. These signals are related to the presence of $\mathrm{Si}$ nitride $\left(\mathrm{SiN}\right.$ and $\left.\mathrm{Si}_{2}\right)$, silicon dioxide $\left(\mathrm{SiO}_{3}\right)$, and silicon oxynitride $(\mathrm{SiON}, \mathrm{SiN})$. Depth scale calibration was performed using a $\mathrm{SiO}_{2}$ film of known thickness as a reference and assuming a constant sputter velocity throughout the ONO stack. The extracted layer thicknesses are in agreement with TEM analysis. In the case of the unoxidized ON stack (C1), [Fig. 1(a)], the presence of a double layer structure is detected. For the oxidized ON sample (C2) [Fig. 1(b)], the $\mathrm{SiO}_{3}$ and $\mathrm{SiON}$ signals reveal a surface oxide layer on top of the remaining nitride.

In the case of sample II [Fig. 1(c)], $\mathrm{SiO}_{3}$ signal shows the formation of a thick silicon oxide layer. In comparison to sample $\mathrm{C} 2$, the SiON signal intensity is higher in the bulk of the nitride layer and extends down to the $\mathrm{Si}$ substrate. This indicates non-negligible oxygen content in the remaining nitride layer and the presence of nitrogen within the tunnel oxide. Moreover, in sample II, the SiN signal exhibits an intense peak at the tunnel oxide/Si-substrate interface with a long tail extending into the Si substrate. The tail is due to a well-known artifact related to mixing phenomena occurring during the sputtering process. The peak at the tunnel oxide/ $\mathrm{Si}$-substrate interface indicates migration of nitrogen atoms toward the Si substrate during the implantation and oxidation processes.

Figure 2 shows typical high-frequency $(1 \mathrm{MHz}) C-V$ characteristics of the ONO structures under study. The measurements were performed in the low-field regime to avoid charge injection and trapping effects. The extracted equivalent oxide thickness of samples II and C2, 14.2 and $8.5 \mathrm{~nm}$, respectively, confirm TEM and ToF-SIMS results regarding the enhanced oxidation of Si-implanted ON stack. Compared to sample $\mathrm{C} 3$, the flatband voltages $\left(V_{\mathrm{FB}}\right)$ of samples $\mathrm{C} 2$ and II are about 1.0 and $0.3 \mathrm{~V}$ shifted to more positive values, respectively. These results are not only in accordance with the previous observations ${ }^{11}$ indicating that oxidation of nitride layer induces a positive shift of $V_{\mathrm{FB}}$ but also reveal that the latter effect is reduced for oxidized Si-implanted nitride 


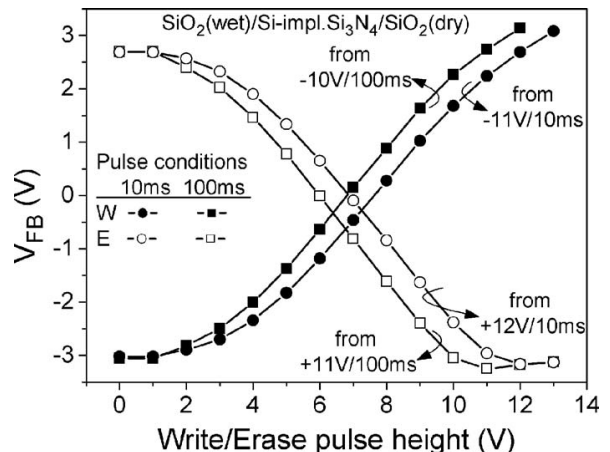

FIG. 3. Write/erase characteristics of Si-implanted-nitride ONO capacitors (sample II) for 10 and $100 \mathrm{~ms}$ pulse duration.

material. In our case, the origin of this effect is probably due to negatively charged defects such as the nitrogen vacancy with attached hydrogen atom. ${ }^{12}$

Memory performance of sample II MONOS devices under write/erase pulsed operation is shown in Fig. 3. Single write (positive) and erase (negative) pulses were applied after setting the devices in near-saturation erase and write states, respectively. Clear saturation is detected in the 10 and $100 \mathrm{~ms}$ erasing regimes. It is believed that such saturation arises from the competitive effects of substrate hole injection and gate electron injection. Memory windows as large as $5.7 \mathrm{~V}$ can be obtained for $100 \mathrm{~ms},+11 /-10 \mathrm{~V}$ and $10 \mathrm{~ms}$, $+12 /-11 \mathrm{~V}$ write/erase pulses, respectively. It should be mentioned that the ONO stack with deposited top oxide (sample C3) exhibits no hole injection under erasing conditions and smaller $V_{\mathrm{FB}}$ shifts in the write regime (e.g., $4.1 \mathrm{~V}$ for $100 \mathrm{~ms}+11 \mathrm{~V}$ ). The absence of hole injection for sample C3 is due to the thick bottom dry oxide used in the present experiments. While the bottom oxide of sample II presents a larger physical thickness, its modified chemical composition allows for efficient erase operation.

Figure 4 shows charge retention characteristics of sample II MONOS devices at 30 and $125^{\circ} \mathrm{C}$. The capacitors were initially charged using $100 \mathrm{~ms},-10$ and $+11 \mathrm{~V}$ pulses for the erase and write states, respectively. The flatband voltage was monitored for waiting times as large as $10^{5} \mathrm{~s}$. The extracted charge (electron) loss rate for the write state was $0.23 \mathrm{~V} /$ decade at $30^{\circ} \mathrm{C}$ and $0.29 \mathrm{~V} /$ decade at $125^{\circ} \mathrm{C}$. In the case of the erase state, charge loss rates of 0.24 and $0.29 \mathrm{~V} /$ decade were found at 30 and $125^{\circ} \mathrm{C}$, respectively. Long time extrapolation indicates $10 \mathrm{yr}$ memory windows of about 3 and $1.5 \mathrm{~V}$ at 30 and $125^{\circ} \mathrm{C}$, respectively.

In summary, it has been presented that a combination of low-energy silicon ion implantation into $\mathrm{ON}$ structures and

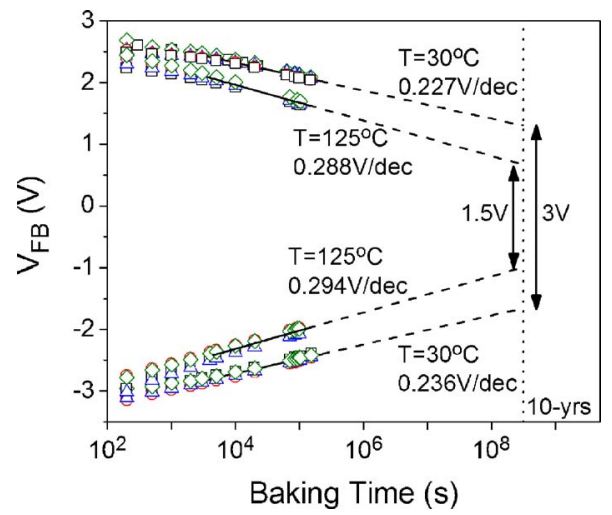

FIG. 4. (Color online) Charge retention characteristics of Si-implantednitride ONO capacitors (sample II) at 30 and $125^{\circ} \mathrm{C}$.

subsequent low-temperature wet oxidation provides an attractive technological route for the fabrication of ONO dielectric stacks. Such a route produces thick and reliable top oxides as well as transforms the nitride layer to silicon oxynitride materials. Both the write/erase and data retention characteristics obtained throughout the measurements performed so far suggest that the ONO stacks reported herein are attractive for the development of nitride storage memory cells.

${ }^{1}$ C. Y. Lu, T. C. Lu, and R. Liu, Proceedings of the 13th International Symposium on the Physical and Failure Analysis of Integrated Circuits (IPFA), Singapore, July 2006, p. 18.

${ }^{2}$ M. H. White, Y. Wang, S. J. Wrazien, and Y. Zhao, Int. J. High Speed Electron. Syst. 16, 479 (2006).

${ }^{3}$ R. van Schaijk, M. Slotboom, M. van Duuren, D. Dormans, N. Akil, R. Beurze, F. Neuilly, W. Baks, A. H. Miranda, and P. G. Tello, Solid-State Electron. 49, 1849 (2006).

${ }^{4}$ L. U. T. Ogbuli and D. T. Jayne, J. Electrochem. Soc. 140, 759 (1993).

${ }^{5}$ H. Du, R. E. Tressler, and K. E. Spear, J. Electrochem. Soc. 136, 3210 (1989).

${ }^{6}$ E. Suzuki, Y. Hayashi, K. Ishii, and T. Tsuchiya, Appl. Phys. Lett. 42, 608 (1982).

${ }^{7}$ M. Saraf, R. Edrei, R. Akhvlediani, Y. Roizin, R. Shima-Edelstein, and A. Hoffman, 24, 1716 (2006).

${ }^{8}$ V. Ioannou-Sougleridis, P. Dimitrakis, V. Em. Vamvakas, P. Normand, C. Bonafos, S. Schamm, A. Mouti, G. Ben Assayag, and V. Paillard, Nanotechnology 18, 215204 (2007).

${ }^{9}$ C. Bonafos, M. Carrada, N. Cherkashin, H. Coffin, D. Chassaing, G. Ben Assayag, A. Claverie, T. Muller, K. H. Heinig, M. Perego, M. Fanciulli, P. Dimitrakis, and P. Normand, J. Appl. Phys. 95, 5696 (2004).

${ }^{10}$ P. Normand, E. Kapetanakis, P. Dimitrakis, D. Skarlatos, K. Beltsios, D. Tsoukalas, C. Bonafos, G. Ben Assayag, N. Cherkashin, A. Claverie, J. A. Van Den Berg, V. Soncini, A. Agarwal, M. Ammen, M. Perego, and M. Fanciulli, Nucl. Instrum. Methods Phys. Res. B 216, 228 (2004).

${ }^{11}$ S. Y. Wang, H. T. Lue, E. K. Lai, L. W. Yang, J. Gong, K. C. Chen, K. Y. Hsieh, J. Ku, and C. Y. Lu, Solid-State Electron. 50, 1171 (2006).

${ }^{12}$ M. Petersen and Y. Roizin, Appl. Phys. Lett. 89, 053511 (2006). 